\title{
Importance of psychosocial status in secondary prevention and rehabilitation of coronary artery disease
}

\author{
Bryan P. McCormick \\ Indiana University, Bloomington, IN, USA
}

Abstract

\begin{abstract}
Lifestyle and behavioral factors play a major part in the development of coronary heart disease (CHD). Rehabilitation and secondary prevention of CHD must likewise consider behavioral and lifestyle change as adjuncts to other therapies. Principal among the psychosocial factors are depression, anxiety and anger/hostility. Related to these negative emotions, a distressed personality style (type-D) in which both negative emotion and social inhibition are present represents a psychosocial risk factor. In addition, social experience, both in the resources available through social networks and the subjective experience of isolation, is related to both the onset and course of CHD. Psychosocial interventions have been found to be effective in rehabilitation and secondary prevention. Finally, a case is made that all professionals working in cardiac rehabilitation and secondary prevention should be knowledgeable in the psychological constructs of motivation and readiness for behavioral change. The widely employed transtheoretical model of change is presented as an example of the need for interventions to be developed that recognize patients' difference in the readiness for change.
\end{abstract}

\section{Introduction}

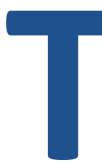
he rehabilitation and secondary prevention of coronary heart disease (CHD) has increasingly acknowledged the effect of psychosocial factors in disease progression. Although psychosocial factors have been recognized as relevant to cardiac rehabilitation for over 30 years, ${ }^{1}$ calls for greater attention to psychosocial status in CHD onset and rehabilitation only began appearing in professional literature in the mid to late 1990 s. $^{2,3}$ At present knowledge of psychosocial factors in CHD are considered core competencies for all professionals working in cardiac rehabilitation and secondary prevention. ${ }^{4}$ This paper reviews recent research in psychosocial risk factors for $\mathrm{CHD}$ as well as implications for rehabilitation and secondary prevention. In addition, motivation and readiness for change are reviewed as a critical consideration in behavioral change as part of both rehabilitation and secondary prevention.

\section{Psychosocial risk factors}

\section{Lifestyle}

Lifestyle and behavior represent one of the most directly modifiable factors in secondary prevention of $\mathrm{CHD}^{5}$ Principal among these risk factors are elevated cholesterol and triglycerides, obesity, high blood pressure, smoking, diabetes and sedentary behavior, and current guidelines for secondary prevention suggest treatment in all areas. ${ }^{6}$ Although these risk factors are appropriately considered as biophysical factors, there is evidence that changes in these biophysical factors may positively affect psychosocial status. For example, even mild improvements in physical fitness have been found to be effective in reducing depression and subsequent mortality ${ }^{6}$ in cardiac rehabilitation. ${ }^{7,8}$ In addition, secondary prevention programs targeting reductions in body mass index (BMI) have also been shown to be effective in reducing depression, improving social functioning and improving emotional functioning. ${ }^{9,10}$

\section{Depression}

Depression remains as one of the most significant psychosocial risk factors in secondary prevention and cardiac rehabilitation. Depression is implicated in both the onset of $\mathrm{CHD}$ as well as the prognosis in rehabilitation. ${ }^{11} \mathrm{Al}-$ though estimates vary, depression confers a relative risk of onset of CHD in the range of 1.5-2.0 in initially healthy individuals. ${ }^{11}$ Among those diagnosed with CHD, rates of clinically significant depression has been identified in $15-20 \%$ of heart failure patients. ${ }^{12,13}$ Depression is also clinically significant for its role in cardiac rehabilitation. Cardiac patients diagnosed with depression demonstrate poorer adherence to cardiac rehabilitation regimen, and increased odds of non-completion. ${ }^{14,15}$ It is worth noting that although there is not strong research evidence, preliminary indications are that the somatic symptoms of depression such as fatigue, sleep disturbance and appetite disturbance have a greater effect on compliance and completion ${ }^{15}$ as well as subsequent cardiac events. ${ }^{16}$ 


\section{Anxiety}

Anxiety has a similar role in CHD to that of depression. First, anxiety increases the odds of the onset of CHD events such as myocardial infarction (MI). ${ }^{17}$ Anxiety appears to have the greatest implications in post-cardiac event outcomes. Particularly among patients post-MI, anxiety increases the odds of adverse events, all cause mortality, cardiac mortality and cardiac events. ${ }^{18-20}$ There are however studies that have failed to find such negative outcomes. ${ }^{21,22}$ Another area of similarity of anxiety to depression relates to compliance with cardiac rehabilitation. As with depression, anxiety is implicated in poor completion rates and higher drop-out rates in rehabilitation, ${ }^{22,23}$ but it also appears to be indicative of the likelihood of readmission ${ }^{24}$ as well as the number of readmissions. ${ }^{25}$

\section{Anger \& Hostility}

As with the other psychosocial factors, anger and hostility are related to the development ${ }^{26}$ and earlier age of onset of cardiac disease. ${ }^{27}$ In addition, high levels of trait anger are associated with increased odds of recurrent cardiac events. ${ }^{28}$ Recent research also indicates that anger may be most relevant to negative cardiac events when it is suppressed. ${ }^{29}$ Specifically, suppressed anger, but not anger alone, was associated with a significantly increased odds of cardiac death or MI. Suppressed anger was highest among those demonstrating a type D personality. In addition, suppressed anger has also been identified as a contributing factor in poor sleep quality among patients with coronary heart disease. ${ }^{30}$ Perhaps more so than other psychosocial factors, the role of anger and hostility among women appears to be different for men and women. In a review of psychosocial factors in the development of CHD in women, Low and colleagues ${ }^{31}$ identified that hostility was less consistently associated with CHD among women as opposed to men.

\section{Type D Personality}

Depression, anxiety and anger have all been increasingly linked with a personality profile characterized as type $\mathrm{D}$ personality. The type $\mathrm{D}$ personality is an extension of early work in the psychosocial factors of CHD that were linked to the type A personality ${ }^{32}$ which was characterized by high degrees of time consciousness, rapidity of movement, impatience, tenseness and overwork. In addition to the time-pressure and impatient characteristics of the original type A conceptualization, the type $\mathrm{D}$ (or distressed) personality is seen to also include general emotional negativity and social inhibition resulting in a general propensity for psychological distress. ${ }^{33} \mathrm{~A}$ recent meta-analysis on type $D$ personality and patients with CHD concluded that the type $D$ personality is significantly associated with increased major adverse cardiac outcomes. ${ }^{34}$ The type $D$ personality has been found to remain as a significant predictor of adverse cardiac events after adjusting for anxiety stress and depression. ${ }^{33}$

\section{Social Networks and Isolation}

In addition to lifestyle and emotional experience, one's social experiences are implicated in CHD risk. First, social experience has been conceptualized both as an objective factor in which social connections and social network size are thought to be indicative of social experience. From this perspective, small social networks (less than 3 individuals) have been found to more than double the odds of cardiac and all cause mortality among patients with $\mathrm{CHD} .{ }^{35}$ In addition, larger social networks have been found to be associated with a decreased incidence of major adverse cardiac events as well as improved overall health,(36) as well as reduced left ventricular mass. ${ }^{37}$ In addition to the objective measures of social experience, subjective approaches to social experience have been explored principally through the examination of social isolation and loneliness. There is evidence that higher perceptions of loneliness are significantly increases the risk of incident CHD; however, this association only appeared to hold true in women. ${ }^{38}$ Finally, social isolation in childhood has been found to be a risk factor for development of behavioral risk factors of CHD in early adulthood. ${ }^{39}$

\section{Psychosocial status in cardiac rehabilitation \& secondary prevention}

\section{Psychosocial Intervention}

Current recommendations related to a comprehensive approach to cardiac rehabilitation and secondary prevention in Europe and the United States demonstrate great similarity (Table I). Both include specific recommendations related to management of psychosocial functioning. Among the skills noted in both of these guides are abilities for professionals to screen for psychological distress including depression, anxiety, anger or hostility, social isolation, marital/family dysfunction, sexual dysfunction and substance abuse. In addition, it is recommended that professionals make appropriate referrals for psychiatric or psychological treatment as warranted by the severity of psychological distress. Finally, comprehensive rehabilitation or secondary prevention programs should offer individual and group education and counseling to address adjustment to disease, stress management and coping strategies.

Meta analyses of the effects of psychosocial interventions have reported significant reduction in subsequent cardiac events and both significant and non-significant reductions in mortality. ${ }^{40,41}$ In addition, psychological interventions do appear to be effective in reducing both depression and anxiety. Psychological interventions were also found to be most effective in reducing depression when they included an intent to treat type-A behaviors; however, interventions focusing on a) education about cardiac risk factors, b) emotional support through client discussion and c) included family members in the treatment process were significantly less effective in affecting depression. ${ }^{41}$ 


\section{Motivation \& Readiness for Change}

As noted previously, the management of lifestyle factors including physical activity, weight, diet and tobacco play a large part in cardiac rehabilitation and secondary prevention (Table II). One of the greatest challenges in cardiac rehabilitation and secondary prevention is that virtually all interventions require behavioral change. As a result, regardless of the type of approach, all interventions should take into account patient motivation and readiness to change. ${ }^{42}$ This should begin with an understanding of patients' motives for behavioral change. Cantor and Sanderson ${ }^{43}$ asserted that goal structures are relevant to understanding motivation for sustained behavior in achieving goals such as behavioral change. Specifically, people whose goals are characterized as approach goals, in which they engage in a behavior due to the behavior's intrinsic value, are found to persist at the behavior even in the face of obstacles and barriers. In contrast, people whose goals are characterized as avoidance goals, in which they engage in a behavior to avoid an undesired outcome, are found to abandon such goals much more readily in the face of obstacles or barriers. This may be highly relevant in cardiac rehabilitation as avoiding future cardiac events may be highly motivating in the short term, but as an avoidance goal sustaining motivation for behavioral change may also be much more difficult in the long term. Thus it should not be surprising that one of the identified psychosocial management competencies for professionals working in cardiac rehabilitation and secondary prevention is the knowledge and skill to implement effective behavior change strategies based on theoretical models of behavior change. ${ }^{4}$

One of the most widely employed models of behavioral change is the transtheoretical model of behavioral change. ${ }^{44}$ This model recognizes that behavior change is a process in which individuals may be at different stages in their readiness and ability for behavioral change. The model presents a series of sequential stages beginning with pre-contemplation, following to contemplation, preparation for change, change action, maintenance of change and includes the possibility for relapse (Table 2). In each of these stages, individuals demonstrate different characteristics and as a result it implies that health professionals should use different strategies in their approach to behavioral change.

For example, in the pre-contemplation stage, people are unaware of the need for change. In the domain of cardiac health and cardiovascular disease, this would be the realm of primary prevention in which the goal would be to make people aware of the impact of their lifestyle and psychosocial functioning on subsequent cardiac health and cardiovascular disease. In contrast, in the contemplation stage, people recognize a need for behavioral change, but still believe that changing behaviors will be much more costly than the benefits of behavior change. As an example, a patient may be informed that his smoking is contributing to high blood pressure and ultimately cardiac disease. Although he recognizes that there are costs to his health if he continues smoking, the benefit he perceives from smoking may outweigh the health costs and so behavioral change is either unlikely or ineffective at this stage. Health professionals working with clients in this stage can support and encourage patients in identifying both the benefits of behavioral change as well as the coping resources necessary to initiate and sustain change. In the preparation stage, an individual has moved one step closer to enacting the change. At this point, although the perceived costs may still outweigh the benefits, the individual accepts that change is needed and prepares to make the change. Health professionals should continue to support patients' internal motivation to change as well as support the development of coping strategies and resources to enable change. In the action stage, patients have made the initial behavioral change ( $<6$ months). In cardiac rehabilitation an initial cardiac event may be the trigger that pushes patients from contemplation stage, through preparation to action. As noted previously however; this motivation for action may be due to a desire to avoid a negative outcome, such as another cardiac event. The challenge for health professionals working with patients at this stage is to find ways to internalize motivation for the new behavior and integrate it into their lifestyle. This internalization and adoption of the new behavior is characteristic of the maintenance stage of the transtheoretical model. Finally, the model recognizes that relapse and return to old behaviors is a possibility. Particularly in the area of cardiac rehabilitation and secondary prevention, significant lifestyle changes are needed. The challenges of initiating and maintaining such changes will have broad impacts to both the patient as well as his or her social environment. Health professionals working in this area should recognize that relapse is not necessarily an indication of failure, but instead an indicator of the difficulty of the change for the patient. Patients may have to work through the stages of change multiple times before new behaviors become a part of their way of life and health professionals must adapt their interventions to the appropriate stage of patients' readiness for change. ${ }^{42}$

\section{Summary}

Psychosocial factors play a significant role in both the onset and course of CHD. Among the most widely recognized factors are depression, anxiety and anger/hostility. Each of these is implicated in initial disease progress as well as prognosis for rehabilitation and subsequent health. In addition, social isolation, although not as well articulated as the above factors, is implicated in disease progress and rehabilitation. There is reason to believe that social isolation is interrelated with other psychosocial factors. As well, although lifestyle interventions typically target improvements in biophysical functioning, they also have the ability to affect psychosocial factors. Finally, efforts to engage patients in behavioral change must be grounded in an understanding of patient motivation and readiness for change. Such knowledge and skills will enable professionals to develop therapeutic regimen that work with patients to mobilize their resources to enact and sustain behavioral change. 
Table 1. Common Elements of Secondary Prevention and Cardiac Rehabilitation

Core Cardiac Rehabilitation Core Competencies for Components and Objectives Cardiac Rehabilitation/ Common to all Clinical Conditions $^{\mathrm{a}}$ Secondary Prevention Professionals: 2010 Update $^{b}$

Patient Assessment Patient Assessment

Physical Activity Counseling Physical Activity Counseling

Exercise Training

Diet/Nutritional Counseling

Weight Control

Management

Lipid Management Exercise Training Evaluation

Blood Pressure Monitoring

Smoking Cessation

Psychosocial Management Nutritional Counseling Weight Management

Lipid Management

Blood Pressure

Management

Tobacco Cessation

Psychosocial Management

Diabetes Management

${ }^{\mathrm{a}}$ From Piepoli et $\mathrm{al}^{6}$; $\mathrm{b}$ From Hamm et $\mathrm{al}^{4}$

Table 2. Transtheoretical stages of changes

\begin{tabular}{|c|c|c|}
\hline Stage & Cost/Benefit & Activities \\
\hline $\begin{array}{l}\text { Pre- } \\
\text { contemplation }\end{array}$ & $\begin{array}{l}\text { No Benefit, } \\
\text { Many cost }\end{array}$ & $\begin{array}{l}\text { Need for behavior } \\
\text { change not recognized }\end{array}$ \\
\hline Contemplation & $\begin{array}{l}\text { Costs >> } \\
\text { Benefits }\end{array}$ & $\begin{array}{l}\text { No action, but } \\
\text { recognized need for } \\
\text { change }\end{array}$ \\
\hline Preparation & $\begin{array}{l}\text { Costs > } \\
\text { Benefits }\end{array}$ & $\begin{array}{l}\text { No action, considering } \\
\text { process for change }\end{array}$ \\
\hline Action & $\begin{array}{l}\text { Benefits > } \\
\text { Costs }\end{array}$ & $\begin{array}{l}\text { Initial behavior change } \\
\text { (<6mos) }\end{array}$ \\
\hline Maintenance & $\begin{array}{l}\text { Benefits }>> \\
\text { Costs }\end{array}$ & $\begin{array}{l}\text { Internalize motivation. } \\
\text { Adopting as lifestyle }\end{array}$ \\
\hline Relapse & $\begin{array}{l}\text { Benefits? } \\
\text { Costs? }\end{array}$ & $\begin{array}{l}\text { Behavior change } \\
\text { interrupted by } \\
\text { occasional relapse }\end{array}$ \\
\hline
\end{tabular}

aProchaska and DiClemente ${ }^{44}$

\section{References}

1. Thoreson RW, Ackerman M. Cardiac rehabilitation - Basic principles and psychosocial factors. Rehabilitation Counseling Bulletin 1981;24(3):223-55

2. Hoffmann A. Cardiac rehabilitation - A controversy. Schweizerische Medizinische Wochenschrift [Article; Proceedings Paper] 1993;123(7):289-93.

3. Hemingway $\mathrm{H}$, Marmot M. Evidence based cardiology - Psychosocial factors in the aetiology and prognosis of coronary heart disease: systematic review of prospective cohort studies. $\mathrm{Br}$ Med J 1999;318(7196):1460-+

4. Hamm LF, Sanderson BK, Ades PA, Berra K, Kaminsky LA, Roitman JL, et al. Core Competencies for Cardiac Rehabilitation/Secondary Prevention Professionals: 2010 Update Position statement of the American Association of Cardiovascular and Pulmonary Rehabilitation Journal of Cardiopulmonary Rehabilitation and Prevention 2011;31(1):2-10.

5. Skinner JS, Cooper A. Secondary prevention of ischaemic cardiac events. Clinical evidence 2011;2011.

6. Piepoli MF, Corra U, Benzer W, Bjarnason-Wehrens B, Dendale P, Gaita D, et al. Secondary prevention through cardiac rehabilita- tion: from knowledge to implementation. A position paper from the Cardiac Rehabilitation Section of the European Association of Cardiovascular Prevention and Rehabilitation. European Journal of Cardiovascular Prevention \& Rehabilitation 2010;17(1):1 17.

7. Milani RV, Lavie CJ. Impact of cardiac rehabilitation on depression and its associated mortality. Am J Med. 2007 Sep;120(9):799-806.

8. Merrill RM, Taylor P, Aldana SG. Coronary Health Improvement Project CHIP) is associated with improved nutrient intake and decreased depression. Nutrition 2008;24(4):314-21.

9. Merrill RM, Aldana SG. Improving Overall Health Status Through the CHIP Intervention. American Journal of Health Behavior 2009;33(2):135-46.

10. Thieszen CL, Merrill RM, Aldana SG, Diehl HA, Mahoney ML, Greenlaw RL, et al. The Coronary Health Improvement Project (chip) for lowering weight and improving psychosocial health. Psychol Rep 2011;109(1):338-52.

11. Lett HS, Blumenthal JA, Babyak MA, Sherwood A, Strauman T, Robins $C$, et al. Depression as a risk factor for coronary artery disease: Evidence, mechanisms, and treatment. Psychosom Med. 2004 May-Jun;66(3):305-15

12. Rutledge T, Reis VA, Linke SE, Greenberg BH, Mills PJ. Depression in heart failure - A meta-analytic review of prevalence, intervention effects, and associations with clinical outcomes. J Am Coll Cardiol 2006;48(8):1527-37.

13. Pozuelo L, Zhang JP, Franco K, Tesar G, Penn M, Jiang W. Depression and heart disease: What do we know, and where are we headed? Cleveland Clinic Journal of Medicine 2009;76(1):59-70.

14. Swardfager W, Herrmann N, Marzolini S, Saleem M, Farber SB, Kiss A, et al. Major Depressive Disorder Predicts Completion, Adherence, and Outcomes in Cardiac Rehabilitation: A Prospective Cohort Study of 195 Patients With Coronary Artery Disease. J Clin Psychiatry 2011;72(9):1181-8.

15. Casey E, Hughes JW, Waechter D, Josephson R, Rosneck J. Depression predicts failure to complete phase-II cardiac rehabilitation. J Behav Med 2008;31(5):421-31.

16. Hoen PW, Whooley MA, Martens EJ, Na B, van Melle JP, de Jonge P. Differential Associations Between Specific Depressive Symptoms and Cardiovascular Prognosis in Patients With Stable Coronary Heart Disease. J Am Coll Cardiol 2010;56(11):838-44.

17. Shen B-J, Avivi YE, Todaro JF, Spiro A, III, Laurenceau J-P, Ward $K D$, et al. Anxiety characteristics independently and prospectively predict myocardial infarction in men. J Am Coll Cardiol 2008;51(2):113-9.

18. Roest AM, Martens EJ, Denollet J, de Jonge P. Prognostic Association of Anxiety Post Myocardial Infarction With Mortality and New Cardiac Events: A Meta-Analysis. Psychosom Med 2010;72(6):563-9

19. Huffman JC, Smith FA, Blais MA, Januzzi JL, Fricchione GL. Anxiety, independent of depressive symptoms, is associated with in-hospital cardiac complications after acute myocardial infarction. J Psychosom Res 2008;65(6):557-63.

20. Shibeshi WA, Young-Xu Y, Blatt CM. Anxiety worsens prognosis in patients with coronary artery disease. J Am Coll Cardiol 2007;49(20):2021-7.

21. Hosseini SH, Yousefnejad K, Tabiban S, Nesarhoseyni V, Bagheri $B$, Kiasari AM, et al. Effects of depression and anxiety symptoms on cardiac mortality following myocardial infarction: A 2-year follow-up. International Journal of Psychiatry in Clinical Practice 2011;15(2):91-6.

22. Tully PJ, Pedersen SS, Winefield HR, Baker RA, Turnbull DA, Denollet J. Cardiac morbidity risk and depression and anxiety: A disorder, symptom and trait analysis among cardiac surgery patients. Psychology Health \& Medicine 2011;16(3):333-45.

23. McGrady A, McGinnis R, Badenhop D, Bentle M, Rajput M. Effects of Depression and Anxiety on Adherence to Cardiac Rehabilitation. Journal of Cardiopulmonary Rehabilitation and Prevention 2009;29(6):358-64.

24. Volz A, Schmid J-P, Zwahlen M, Kohls S, Saner H, Barth J. Predictors of readmission and health related quality of life in patients with chronic heart failure: a comparison of different psychosocial aspects. J Behav Med 2011;34(1):13-22. 
25. Turner A, Phillips L, Hambridge JA, Baker AL, Bowman J, Colyvas $\mathrm{K}$. Clinical outcomes associated with depression, anxiety and social support among cardiac rehabilitation attendees. Aust N Z J Psychiatry 2010;44(7):658-66.

26. Player MS, King DE, Mainous AG, III, Geesey ME. Psychosocial factors and progression from prehypertension to hypertension or coronary heart disease. Annals of Family Medicine 2007;5(5):403-11.

27. Ketterer M, Rose B, Knysz W, Farha A, Deveshwar S, Schairer J, et al. Is social isolation/alienation confounded with, and non-independent of, emotional distress in its association with early onset of coronary artery disease? Psychology Health \& Medicine 2011;16(2):238-47.

28. Song EK, Son Y-J, Lennie TA. Trait anger, hostility, serum homocysteine, and recurrent cardiac events after percutaneous coronary interventions. Am J Crit Care 2009;18(6):554-61.

29. Denollet J, Gidron Y, Vrints CJ, Conraads VM. Anger, Suppressed Anger, and Risk of Adverse Events in Patients With Coronary Artery Disease. Am J Cardiol 2010;105(11):1555-60.

30. Caska CM, Hendrickson BE, Wong MH, Ali S, Neylan T, Whooley MA. Anger Expression and Sleep Quality in Patients With Coronary Heart Disease: Findings From the Heart and Soul Study. Psychosom Med 2009;71(3):280-5.

31. Low CA, Thurston RC, Matthews KA. Psychosocial Factors in the Development of Heart Disease in Women: Current Research and Future Directions. Psychosom Med. 2010 Nov-Dec;72(9):842-54.

32. Friedman M, H RR. Type A behavior and your heart. New York: Knopf; 1974.

33. Denollet J, Conraads VM. Type D personality and vulnerability to adverse outcomes in heart disease. Cleve Clin J Med 2011;78 Suppl 1:S13-9.

34. O’Dell KR, Masters KS, Spielmans GI, Maisto SA. Does type-D personality predict outcomes among patients with cardiovascular disease? A meta-analytic review. J Psychosom Res 2011;71(4):199-206.
35. Brummett BH, Barefoot JC, Siegler IC, Clapp-Channing NE, Lytle $\mathrm{BL}$, Bosworth HB, et al. Characteristics of socially isolated patients with coronary artery disease who are at elevated risk for mortality. Psychosom Med 2001;63(2):267-72.

36. Shaya FT, Yan X, Farshid M, Barakat S, Jung M, Low S, et al. Social networks in cardiovascular disease management. Expert Review of Pharmacoeconomics \& Outcomes Research 2010;10(6):701-5.

37. Rodriguez CJ, Elkind MSV, Clemow L, Jin Z, Di Tullio M, Sacco RL, et al. Association between Social Isolation and Left Ventricular Mass. Am J Med 2011;124(2):164-70.

38. Thurston RC, Kubzansky LD. Women, Loneliness, and Incident Coronary Heart Disease. Psychosom Med 2009;71(8):836-42.

39. Caspi A, Harrington H, Moffitt TE, Milne BJ, Poulton R. Socially isolated children 20 years later - Risk of cardiovascular disease. Arch Pediatr Adolesc Med 2006;160(8):805-11.

40. Mueller-Riemenschneider F, Meinhard C, Damm K, Vauth C, Bockelbrink A, Greiner W, et al. Effectiveness of nonpharmacological secondary prevention of coronary heart disease. European Journal of Cardiovascular Prevention \& Rehabilitation 2010;17(6):688-700.

41. Whalley B, Rees K, Davies P, Bennett P, Ebrahim S, Liu Z, et al. Psychological interventions for coronary heart disease. Cochrane Database of Systematic Reviews 2011(8).

42. Collins CA, Butryn ML, Jennings EG. Readiness for change in cardiac rehabilitation programs. In: Kraus WE, Keteyian SJ, editors. Cardiac Rehabilitation. Totowa, NJ: Springer 2007; p. 67-76.

43. Cantor N, Sanderson CA. Life task participation and well-being: The importance of taking part in daily life. In: Kahneman D, Diener E, Schwartz N, editors. Well-being : The foundations of hedonic psychology New York: Russell Sage Foundation 1999; p. 230-43.

44. Prochaska JO, DiClemente CC. The transtheoretical approach. In: Norcross JC, Goldfried MR, editors. Handbook of Psychotherapy Integration. 2nd ed. New York: Oxford University Press; 2005. 